\title{
Negative Air Pressure on Wet Cupping in Decreasing Blood Pressures in Hypertensive Patients
}

\author{
Budi Darmawan $^{1}$, Diyah Fatmasari ${ }^{2}$, Rr. Sri Endang Pujiastuti ${ }^{3}$ \\ ${ }^{1}$ Postgraduate Program, Poltekkes Kemenkes Semarang, Indonesia \\ ${ }^{2,3}$ Department of Nursing, Poltekkes Kemenkes Semarang, Indonesia \\ Corresponding Author: Budi Darmawan (budi.di77@gmail.com)
}

\begin{abstract}
Background: Wet cupping, furthermore mentioned cupping, decreases blood pressures through the level of negative air pressures added by hydrostatics filtration pressure to reinforce the power of fluids filtration in capillaries. However, an appropriate negative air pressure to decrease blood pressure remains an uncertainty.

Purpose: This study aimed to analyze negative air pressure differences on cupping in decreasing blood pressures in hypertensive patients.

Methods: This is a quasi-experimental design conducted in three Community Health Centers in Langsa City, Aceh, Indonesia. The samples were 36 hypertensive males with age from 45 to 55, who were randomly stratified into two groups with cupping pressures 400 mbar $(n=18)$ as the control group; and 540 mbar $(n=18)$ as the intervention group. The cupping session was performed to each group on T1 (alkahil) point and in the middle line of both shoulders blade points. The systolic blood pressure (SBP) and diastolic blood pressures (DBP) were measured by validated automatic sphygmomanometer. The follow-up periods were one week and two weeks. The data were then analyzed by repeated measures ANOVA.

Results: Cupping pressure of 400 mbar decreased the mean of SBP and DPB with a pvalue of 0.450 and 0.026 , respectively after two weeks of intervention. Meanwhile, cupping pressure of 540 mbar decreased the mean of SBP and DBP with a p-value of 0.006 and 0.057 , respectively. Tests of within-subjects resulted in the p-value of 0.250 (SBP) and 0.176 (DBP) after two weeks of intervention. There were no significant differences in SBP and DBP between the intervention group and the control group.

Conclusion: The cupping pressure between 400 mbar and 540 mbar could reduce blood pressure; however, the cupping pressure of 540 mbar yielded greater effect in decreasing blood pressure than the 400 mbar. Negative air vacuum pressure loads on cupping to decrease blood pressure should be considered between 400 to 540 mbar, and further studies are needed.
\end{abstract}

Keywords: Blood pressure; hypertension; negative air pressure; wet cupping

\section{BACKGROUND}

Hypertension had higher incidences in men while females tend to have hypertension after menopause periods. Men had the higher risk of hypertension incidences than females until 55 years old (Fernández-Atucha et al., 2017). Hypertension is defined as systolic blood pressure (SBP) $\geq 140 \mathrm{mmHg}$ and or diastolic blood pressure (DBP) $\geq 90$ 
$\mathrm{mmHg}$. Hypertension led to the stroke, retinopathy of blindness, coronary heart diseases to cardiac failure, chronic kidney failure to terminal kidneys failure (Bild et al., 2014).

Pharmacological treatments of hypertension such as diuretics, sympathetic inhibitors, beta blockers, vasodilators, angiotensin-converting enzyme inhibitors, calcium angiotensin, and angiotensin II receptor blocker decrease BP by influencing heart and blood vessels or both (Wahdah, 2011). Long-term use of pharmacological treatment arises several side effects even caused resistance that impacted upon the treatment effectiveness (Kalra, Kalra, \& Agrawal, 2010).

Non-pharmacological treatment is enhanced to reduce blood pressure. Several studies revealed that blood pressure could be lowered by yoga (Posadzki, Cramer, Kuzdzal, Lee, \& Ernst, 2014), acupuncture (Luo, Xu, \& Liu, 2015; Zhao et al., 2015), herbal (Xiong, Li, Zhang, \& Wang, 2015) and cupping (Aleyeidi, Aseri, \& Kawthar, 2015; Aleyeidi, Aseri, Matbouli, Sulaiamani, \& Kobeisy, 2015). Several studies about cupping on hypertension by Aleyeidi, Aseri, \& Kawthar (2015); Aleyeidi, Aseri, Matbouli, et al. (2015); Kusyati, Hartono, \& Hastuti (2014) and Zarei, Hejazi, Javadi, \& Farahani (2012) proved that cupping results in a significant decrease of BP and reduces risks, severity, and complications of hypertension.

Cupping therapy is a simple procedure in which negative pressure is applied to the skin through sucking cups. Cupping is a simple therapy that can be performed in various diseases with different etiologies and pathogeneses as hypertension. Blood vessels in the cupped region are dilated by the action of vasodilators such as adenosine, noradrenaline, and histamine which are known to increase the circulation of blood, and stimulate autonomic nervous system to decrease blood pressures (BP) (Zarei et al., 2012). Cupping stimulates endogenous nitric oxide production and excretion of accumulated vasoactive substances and free radicals, which may reduce BP (Aleyeidi, Aseri, Matbouli, et al., 2015).

Cupping benefits homeostasis in circulation. Mechanism of cupping works on the suction pressures, nitric oxide production and skin scarifications (openings in skin barrier) in enhancing natural excretory skin functions, improving lymphatic and capillary circulations and restoring homeostasis. Skin scarifications and negative air pressures enhanced capillary infiltration leading to excretion of collected interstitial fluids (including lymph) with Causative Pathological Substances (CPS), which includes both disease-causing substances and disease-related substances resulting during disease pathogenesis (El Sayed, Mahmoud, \& Nabo, 2013).

Vacuum pressures developed inside the cup are calculated using Boyle's Law as reported by Tham, Lee, and Lu (2006) with measured volumes of the cup $(80.0 \mathrm{ml}, \mathrm{r}=50$ $\mathrm{mm})$ and pumping chamber $(41.5 \mathrm{ml})$ in the hand-pump, and by assuming that the handpump has a pumping efficiency of about $60-65 \%$. The vacuum pressures corresponding to one and two pumps of the manual hand-pump were estimated to be about 141 and 254 mbar respectively $(1 \mathrm{mbar}=1 \mathrm{hPa}=0.75 \mathrm{mmHg}=14.7 \mathrm{psi})$. Huber, Emerich, and Braeunig (2011) reported advanced practitioners were successful in holding a constant 
level of negative pressure, typically around $-400 \mathrm{hPa}$. The effect of the cupping may be quite different by drifting low pressures.

Several studies about cupping on hypertension did not report negative air pressure loads (Aleyeidi, Aseri, \& Kawthar, 2015; Aleyeidi, Aseri, Matbouli, et al., 2015; Kusyati, Hartono, \& Hastuti, 2014; and Zarei, Hejazi, Javadi, \& Farahani 2012). According to an experienced cupping therapy practitioner as the expert consultant, cupping practitioners usually use twice to three time pumping when they perform cupping. Referencing to Huber et al. (2011), this study assumed that the estimated negative air pressure used in the study by cupping practitioners on hypertension mentioned above was 400 mbar, and by adding one time pumping referenced to Tham et al. (2006) that estimated about \pm 141 mbar, the vacuum pressure was about 540 mbar. Nevertheless, the appropriate negative air pressure loads to decrease BP remain an uncertainty.

\section{PURPOSE}

This study aimed to analyze negative air pressure differences on cupping in decreasing blood pressure in patients with hypertension.

\section{METHODS}

This study is an experimental pre-post control study conducted in three Community Health Centers in Langsa City, Aceh province, Indonesia, started from November 2016 to February 2017. The ethics and legality of this study were approved by the Health Polytechnic of Semarang Research Ethics Committee. This study involved one group of subjects who underwent cupping with negative air pressure $\pm 400 \mathrm{mbar}$ (a control group) and another group on pressure \pm 540 mbar (an intervention group) in addition to the conventional hypertension treatment.

The subjects were recruited by stratified random assignment. The inclusion criteria were hypertension with systolic blood pressure $\geq 140 \mathrm{mmHg}$ or diastolic blood pressure $\geq 90$ $\mathrm{mmHg}$, never receiving cupping or at least one month earlier, males, and age of 45-55 years old. Samples of any conditions neither contraindicated to cupping, e.g., anemia, chronic lung diseases, required blood anti-coagulating treatment nor consumed hypertension drugs $<12$ hours before cupping nor had skin lesion at cupping point were excluded.

Subject's eligibility was checked and written informed consent was obtained. Stratified random assignment was conducted to assign subjects to the control group or to the intervention group, and the subjects were randomized into each group by identifying the subject's grade of hypertension as grade 1 (SBP 140-159/ DBP 90-99 mmHg), grade 2 (160-179/100-109 $\mathrm{mmHg}$ ), and grade 3 ( $\geq 180 \geq 110 \mathrm{mmHg}$ ) (Asayama et al., 2014). Subjects were selected by choosing each grade written outside of the envelopes randomly by the researchers and assigned according to " 400 " or " 540 " written on a piece of paper inside the envelopes. To preserve concealment, the randomization was performed using sealed opaque envelopes, such that neither the patient nor the observer could predict the group to which a subject was assigned. Subjects confidentiality and privacy were ensured throughout the study, and subjects were free to exit the study whenever they desired (Pujiastuti, 2016). 
The cupping was performed by the researchers that were certified for cupping therapy under the supervision of an advanced cupping therapy practitioner. The procedure of cupping in both groups was begun with cleaning the back of the body using alcohol $70 \%$; when dried, olive oil was applied all over the back, then slide the cup alongside the meridian using long strokes for three minutes to resolve blood stagnation, manipulate the excess pathogen and bring up the heat to surface of the skin. Cupping glass (5 $\mathrm{cm}$ in diameter) was applied in three sites at the back of the body on T1 (alkahil) point and the middle line of both shoulders blade points, continued with adjusting the vacuum power pressure using manual hand pump to create the pressure $\pm 400 \mathrm{mbar}$ that equal to two times full pumping (Huber et al., 2011) in the control group, and adding one full pumping that estimated about \pm 141 mbar (Tham et al., 2006) to create pressure \pm 540 mbar that equal to three times full pumping in the intervention group. The cup was then gently removed after three minutes, and 15 very superficial incisions were made parallel to each other using a surgical blade on cupping sites with $\pm 0.5 \mathrm{~cm}$ long. After creating the incisions, the cup was placed over the same area, and the suctioning was repeated for three minutes with identical vacuum pressure power by measuring the height of the bulging skin inside the cup during cupping using a regular ruler $(400 \mathrm{mbar}= \pm 20 \mathrm{~mm}$ and $540 \mathrm{mbar}= \pm 23 \mathrm{~mm}$ ). The cupping procedure was repeated three times without repeating the incisions, and then the area was cleaned and dressed to avoid infection (Ahmedi \& Siddiqui, 2014).

BP was measured at baseline, and the follow-up periods were one week and two weeks after the cupping. For BP measurement, we followed the BP measurement standards recommended by European Health Examination Survey (EHES) measurement guidelines (Tolonen et al., 2015). According to these guidelines, measurements were performed three times respectively with one-minute rest on the right arms in a sitting position upright in a chair with both feet on the floor and back resting against the back of the chair and not cross-legged. Upper arm was bared without constrictive clothing. Next, the BP arm was raised to heart level and laid on the armrest. The subjects were then instructed to relax as much as possible for five minutes prior to applying the correctly sized BP cuff (determination based on upper arm circumference measurement and manufacturer's recommended cuff size) to the upper arm so the lower edge of the BP cuff is \pm 1 inch above the antecubital fossa, with the cuff aligned over the brachial artery at the designated location on the cuff. The subjects were asked not to talk as the $\mathrm{BP}$ was measured, then the BP measurement button on the automated device was activated. All BP measurements were performed using a validated, automatic sphygmomanometer (OMRON 7203; Japan) to minimize observer bias. The instructions provided by the device manufacturer were carefully followed for the measurements. BP was recorded three times during each visit, and the mean value was documented and recorded as BP data of subjects in this study.

Statistical analysis was performed with SPSS version 18.0. The data of subject characteristics were analyzed using frequencies and percentages. Systolic blood pressure (SBP) and diastolic blood pressure (DBP) data at every measurement for each group of subjects were first tested for normality (Shapiro-Wilk) and homogeneity (Levene's test) as a condition for ANOVA parametric test. The results of blood pressure 
measurement between before cupping, one week and two weeks after cupping were compared in each group and between groups using repeated measure ANOVA with the pairwise comparison as post-hoc.

\section{RESULTS}

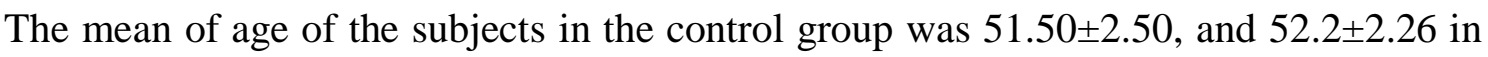
the intervention group with a minimum age of 47 years and maximum of 55 years. The mean of BMI was highest in the control group that was $25.06 \pm 1.61 \mathrm{~kg} / \mathrm{m} 2$. The majority of subjects' education was Senior High School (44.4\%) in the control group. Subjects consuming the most types of antihypertensive drugs were 7 people $(38.9 \%)$ in the control group (Amlodipine $5 \mathrm{mg}$ ) and 7 people (38.9\%) in the intervention group (Amlodipine $10 \mathrm{mg}$ ). Homogeneity and frequencies of subject's characteristics as baseline variables are presented in Table 1, without statistically significant differences between any of the baseline variables.

Table 1. Homogeneity and frequencies characteristics of subjects $(n=36)$

\begin{tabular}{|c|c|c|c|c|c|c|c|}
\hline \multirow{2}{*}{ Variables } & \multicolumn{3}{|c|}{ Control group $(n=18)$} & \multicolumn{3}{|c|}{ Intervention group $(n=18)$} & \multirow[t]{2}{*}{$p$} \\
\hline & $f$ & $\%$ & Mean \pm SD & $\mathrm{f}$ & $\%$ & Mean \pm SD & \\
\hline Ages & & & $51.50 \pm 2.50$ & & & $52.2 \pm 2.26$ & $0.583^{*}$ \\
\hline BMI & & & $25.06 \pm 1.61$ & & & $24.93 \pm 2.10$ & $0.087 *$ \\
\hline \multicolumn{8}{|l|}{ Educations } \\
\hline Junior High Schools & 5 & 27.8 & & 5 & 27.8 & & $0.924 * *$ \\
\hline Senior High Schools & 8 & 44.4 & & 7 & 38.9 & & \\
\hline Bachelor's degree & 5 & 27.8 & & 6 & 33.3 & & \\
\hline \multicolumn{8}{|l|}{ Anti-hypertension drugs } \\
\hline Amlodipine $5 \mathrm{mg}$ & 7 & 38.9 & & 5 & 27.8 & & $0.604 * *$ \\
\hline Amlodipine $10 \mathrm{mg}$ & 4 & 22.2 & & 7 & 38.9 & & \\
\hline Nifedipin 10 mg & 2 & 11.1 & & 3 & 16.7 & & \\
\hline Captopril $25 \mathrm{mg}$ & 5 & 27.8 & & 3 & 16.7 & & \\
\hline \multicolumn{8}{|c|}{ * Levene test of homogeneity of variance; **Chi square; BMI=Body Mass Index $\left(\mathrm{kg} / \mathrm{m}^{2}\right)$} \\
\hline \multicolumn{8}{|c|}{$\begin{array}{l}\text { Table 2. Homogeneity and frequencies of smoking, drinking coffee, and a low-sodium } \\
\text { diet of subjects }\end{array}$} \\
\hline \multirow{2}{*}{ Variables } & \multicolumn{3}{|c|}{ Control group $(n=18)$} & \multicolumn{3}{|c|}{ Intervention group $(n=18)$} & $p^{*}$ \\
\hline & & $\mathrm{f}$ & $\%$ & & f & $\%$ & \\
\hline \multicolumn{8}{|l|}{ Smoking } \\
\hline Yes & & 4 & 22.2 & & 2 & 11.1 & 0.371 \\
\hline No & & 14 & 77.8 & & 16 & 88.9 & \\
\hline \multicolumn{8}{|l|}{ Drinking coffee } \\
\hline Yes & & 8 & 44.4 & & 5 & 27.8 & 0.298 \\
\hline No & & 10 & 55.6 & & 13 & 77.2 & \\
\hline \multicolumn{8}{|l|}{ Low-sodium diet } \\
\hline Yes & & 4 & 22.2 & & 3 & 16.7 & 0.674 \\
\hline No & & 14 & 77.8 & & 15 & 83.3 & \\
\hline
\end{tabular}


Table 2 presents the test results of homogeneity and frequency of daily habits of subjects, and no significant difference was found. Subjects in the intervention group (88.9) did not smoke but had a history of smoking habit, while subjects in the control group drank coffee habitually $(44.4 \%)$. Subjects $(77.8 \%)$ in the control group and subjects $(83.3 \%)$ in the intervention group did not adhere to a low-sodium diet.

Table 3 presents the grade of hypertension before cupping at a baseline; both groups had 12 subjects (66.7\%) in grade 1 and 6 subjects (33.3\%) in grade 2 hypertension with no significant differences.

Table 3. Homogeneity, mean and frequency of hypertension grade in each group

\begin{tabular}{|c|c|c|c|c|c|}
\hline \multirow{2}{*}{ Categories } & \multicolumn{2}{|c|}{ Control group $(n=18)$} & \multicolumn{2}{|c|}{ Intervention group $(n=18)$} & \multirow[t]{2}{*}{$p^{*}$} \\
\hline & $\mathrm{f}$ & $\%$ & $\mathrm{f}$ & $\%$ & \\
\hline Systolic $($ Mean \pm SD)** & \multicolumn{2}{|c|}{$(156.72 \pm 10.25)$} & \multicolumn{2}{|c|}{$(156.22 \pm 10.70)$} & \\
\hline Grade 1 (140-159) & 12 & 66.7 & 12 & 66.7 & \\
\hline Grade 2 (160-179) & 6 & 33.3 & 6 & 33.3 & 0.779 \\
\hline Grade $3(\geq 180)$ & 0 & 0.0 & 0 & 0.0 & \\
\hline Diastolic(Mean $\pm \mathrm{SD})^{* *}$ & \multicolumn{2}{|c|}{$(99.72 \pm 4.46)$} & \multicolumn{2}{|c|}{$(98.33 \pm 4.46)$} & \\
\hline Grade 1 (90-99) & 9 & 50.0 & 8 & 44.4 & \\
\hline Grade 2 (100-109) & 9 & 50.0 & 10 & 55.6 & 0.861 \\
\hline Grade $3(\geq 110)$ & 0 & 0.0 & 0 & 0.0 & \\
\hline
\end{tabular}

The comparisons of mean BP within the group as presented in table 4 show that the intervention group had a significant difference in reducing SBP in the week I $(p=0.006)$ and week II $(p=0.006)$. In addition, the DBP significantly reduced in the week I $(p=0.004)$ and nearly significant in week II $(p=0.057)$. On the other hand, there were no significant differences of SBP $(p=0.439)$ and DBP $(p=0.398)$ in the intervention group between week I and week II.

Table 4. The pairwise comparison differences on blood pressure by each measurement times within the groups

\begin{tabular}{|c|c|c|c|c|c|c|}
\hline \multirow{2}{*}{$\begin{array}{l}\text { Group of subjects } \\
\text { Control group }\end{array}$} & \multirow{2}{*}{$\begin{array}{c}\text { BP } \\
\text { SBP }\end{array}$} & \multicolumn{4}{|c|}{ Measurement Times } & \multirow{2}{*}{$\frac{p^{*}}{0.119}$} \\
\hline & & before & $156.72 \pm 10.25$ & week I & $154.94 \pm 9.32$ & \\
\hline & & week I & $154.94 \pm 9.32$ & week II & $155.61 \pm 9.67$ & 0.605 \\
\hline & & before & $156.72 \pm 10.25$ & week II & $155.61 \pm 9.67$ & 0.450 \\
\hline \multirow[t]{3}{*}{ Intervention group } & & before & $156.22 \pm 10.70$ & week I & $152.94 \pm 7.35$ & 0.006 \\
\hline & & week I & $152.94 \pm 7.35$ & week II & $151.94 \pm 9.12$ & 0.439 \\
\hline & & before & $156.22 \pm 10.70$ & week II & $151.94 \pm 9.12$ & 0.006 \\
\hline \multirow[t]{3}{*}{ Control group } & DBP & before & $99.72 \pm 4.46$ & week I & $98.06 \pm 4.49$ & 0.085 \\
\hline & & week I & $98.06 \pm 4.49$ & week II & $97.22 \pm 2.63$ & 0.366 \\
\hline & & before & $99.72 \pm 4.46$ & week II & $97.22 \pm 2.63$ & 0.026 \\
\hline \multirow[t]{3}{*}{ Intervention group } & & before & $98.33 \pm 4.46$ & week I & $95.44 \pm 4.05$ & 0.004 \\
\hline & & week I & $95.44 \pm 4.05$ & week II & $96.22 \pm 1.59$ & 0.398 \\
\hline & & before & $98.33 \pm 4.46$ & week II & $96.22 \pm 1.59$ & 0.057 \\
\hline
\end{tabular}

*Repeated Measure ANOVA $(\mathrm{p}<0.05) ; \quad \mathrm{BP}=$ Blood pressure; $\mathrm{SBP}=$ Systolic Blood Pressure; DBP=Diastolic Blood Pressure 
Figure 1 and 2 show the mean SBP and DBP differences respectively on each measurement in both groups.

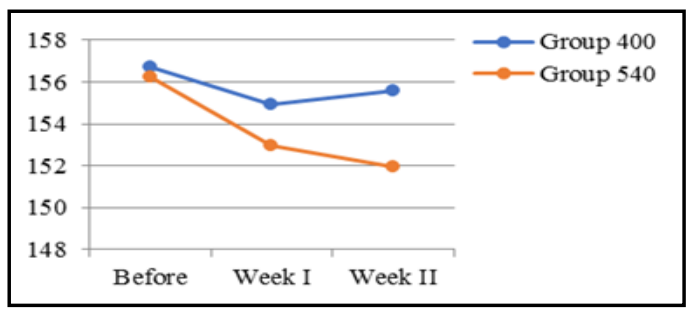

Figure 1. The mean SBP differences on each measurement.

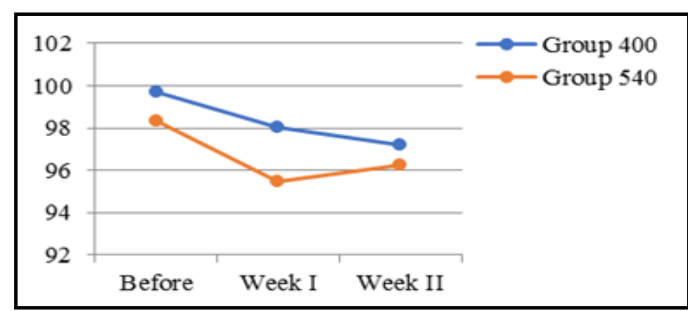

Figure 2. The mean DPB differences on each measurement.

Table 5 shows the comparison of BP mean at before, week I, and week II with $p=0.887$, $p=0.479$, and $p=0.250$, respectively. There was no significant difference between both of pressures amounts; thus, negative air pressure differences did not provide a significant difference in decreasing SBP on the subjects in both groups. When comparing DBP at before $(p=0.357)$, week I $(p=0.076)$ and week II $(p=0.176)$, there was no significant difference between the two amounts of pressure; thus, a negative air pressure difference did not provide a significant difference in decreasing DBP in both groups. Although there was no significant difference between both group with $p=0.250$, the mean SBP in the intervention group decreased about 3.67 \pm 3.31 compared with the control group in week II.

Table 5. The comparison of BP mean by each measurement time between the control group and the intervention group.

\begin{tabular}{|c|c|c|c|c|}
\hline Variables & Group of subjects & Mean \pm SD & Mean difference $\pm \mathrm{SE}$ & $p^{*}$ \\
\hline \multirow{2}{*}{$\begin{array}{l}\text { SBP } \\
\text { before }\end{array}$} & & & \multirow[b]{2}{*}{$0.50 \pm 3.49$} & \multirow[b]{2}{*}{0.887} \\
\hline & $\begin{array}{l}\text { Control group } \\
\text { Intervention group }\end{array}$ & $\begin{array}{l}156.72 \pm 10.25 \\
156.22 \pm 10.70\end{array}$ & & \\
\hline week I & $\begin{array}{l}\text { Control group } \\
\text { Intervention group }\end{array}$ & $\begin{array}{l}154.94 \pm 9.32 \\
152.94 \pm 7.35\end{array}$ & $2.00 \pm 2.80$ & 0.479 \\
\hline week II & $\begin{array}{l}\text { Control group } \\
\text { Intervention group }\end{array}$ & $\begin{array}{l}155.61 \pm 9.67 \\
151.94 \pm 9.12\end{array}$ & $3.67 \pm 3.31$ & 0.250 \\
\hline $\begin{array}{l}\text { DBP } \\
\text { before }\end{array}$ & $\begin{array}{l}\text { Control group } \\
\text { Intervention group }\end{array}$ & $\begin{array}{l}99.72 \pm 4.46 \\
98.33 \pm 4.46\end{array}$ & $1.39 \pm 1.47$ & 0.357 \\
\hline week I & $\begin{array}{l}\text { Control group } \\
\text { Intervention group }\end{array}$ & $\begin{array}{l}98.06 \pm 4.49 \\
95.44 \pm 4.05\end{array}$ & $2.61 \pm 1.42$ & 0.076 \\
\hline week II & $\begin{array}{l}\text { Control group } \\
\text { Intervention group }\end{array}$ & $\begin{array}{l}97.22 \pm 2.63 \\
96.22 \pm 1.59\end{array}$ & $1.00 \pm 0.72$ & 0.176 \\
\hline
\end{tabular}

*Repeated measure ANOVA

There was no significant difference between 400 mbar and 540 mbar negative air pressures load in decreasing BP. The effect size obtained after cupping with different 
Nurse Media Journal of Nursing, 7(2), 2017, 123

negative air pressures load on SBP was 0.40 (medium category), and DBP was 0.46 (medium). The effect size was calculated using Cohen's formula (Zhu, 2016).

\section{DISCUSSION}

\section{Baselines characteristics}

The mean of age of the subjects was $51.86 \pm 2.38$, ranging from 47 to 55 years old. An age limit on this study refers to the opinion that states males had a higher risk of hypertension to the age of 55 years (Fernández-Atucha et al., 2017) and age $\geq 45$ years in males is one of the predisposing factors of hypertension (McNeil \& Parkosewich, 2013). Males at $\geq 55$ years showed a low activity of Angiotensin Converting Enzymes (ACE) than females, while fellow males have a significant decrease in ACE activity that occurs in those aged over 55 years compared with age under 55 years old. In this age, testosterone hormone began to decline in males (21\% at age 55-59 years, $26 \%$ at age 60-69 years, and 31\% at age 70-86 years). This explains the enormous influence of testosterone compared with estrogen on the activities of the ACE in regulating BP (Fernández-Atucha et al., 2017).

The highest mean of body mass index (BMI) in this study was $25.06 \pm 1.608 \mathrm{~kg} / \mathrm{m}^{2}$. People with overweight (BMI 25.1-27.0 kg/m²) or obese (BMI> $27.0 \mathrm{~kg} / \mathrm{m}^{2}$ ) may increase the risk of hypertension by five times when compared with a normal BMI. Asian races had higher body fat percentages even with a lower BMI values. The incidence of hypertension with increased BMI was associated with increased in body fluids volume, peripheral resistance and cardiac output (Albert \& Effiong, 2015).

The majority of subjects' education were senior high school (41.7\%), and bachelor degree $(30.6 \%)$. This characteristic was consistent with a study on risk factors of hypertension conducted by Albert and Effiong (2015) which reported that people with a level of secondary education and higher education has higher incidences of hypertension compared to those with low education level or never attend school at all.

Most subjects consumed anti-hypertensive drug as Amlodipine $5 \mathrm{mg}$ (38.9\%) in the control group and Amlodipine $10 \mathrm{mg}$ (38.9\%) in the intervention group. The use of one type of hypertension drug is only effective in some people, while more than $50 \%$ others require more than one drug to control hypertension BP. The seventh report of the Joint National Committee on prevention, detection, evaluation, and treatment of high blood pressure (JNC 7) guidelines and European Society of Hypertension (ESH), recommended that the treatment with more than one type of antihypertensive medication should be considered if the SBP $>20 \mathrm{mmHg}$ or DBP> $10 \mathrm{mmHg}$ above normal BP in people with high risk of cardiovascular diseases (Kalra et al., 2010).

\section{Habits of the subjects}

Most subjects (77.8\%) in the control group and subjects (88.9\%) in the intervention group did not smoke but had a history of the smoking habit. According to Polosa et al. (2016), it has been estimated that the 10-year fatal cardiovascular risk is doubled in smokers and that for young smokers the risk for myocardial infarction is up to 5-fold higher compared to non-smokers. The risk was primarily related to the amount of tobacco smoked daily and shows a clear dose-response relationship with no obvious 
lower limit for deleterious effects. By sustaining low-grade systemic inflammation and contributing to arterial stiffness, tobacco smoke is also likely to lead to arterial hypertension, thus further worsening smokers' cardiovascular risk profile. Another study reported cigarette smoke alters catecholamine release and increased blood pressure and the risk for hypertension. This increased stiffness leads to elevated SBP and a widened pulse pressure that, in turn, leads to further tension on the arterial wall generating a positive feedback effect (Doonan et al., 2010).

Subjects (44.4\%) in the control group and subjects $(27.8 \%)$ in the intervention group had a habit of drinking coffee. Papakonstantinou et al. (2016) reported coffee consumption significantly increased BP 3 hours post-consumption without differences between coffee types, and temporary hypertensive coffee effect occurred even after small doses of consumed caffeine ( $80 \mathrm{mg} /$ day). The type of coffee consumed may have a different impact on BP suggesting that boiled coffee may cause a higher increase in BP compared to filtered coffee, after daily consumption of large coffee doses ( $>5$ cups) for several days or weeks.

Subjects $(77.8 \%)$ in the control group and subjects $(83.3 \%)$ in the intervention group were not adherent to low-sodium diet or reduced salt intake in daily food. This was in line with the opinion by Albert and Effiong (2015) that mentioned high-salt diet was a risk factor for hypertension. The relationship between salt intake and blood pressure is direct and progressive as there is a dose-response relationship between salt intake and blood pressure in the range of 3-12 g of salt intake per day. Although some studies mention only those individuals with salt sensitivity develop hypertension with increase salt intake, Albert's study found a relationship between salt intakes and stage one hypertension. Another opinion reported, in most people with normal renal function and BP, the kidney is capable of dealing with wide variations in sodium intake, without producing increases in BP. However, in some individuals, moderate changes (1-2 g/day) in sodium intake can exert a substantial effect on BP, a concept called salt sensitivity. A physiological consequence of low sodium intake is activation of the renin-angiotensinaldosterone system (RAAS) and catecholamine (O'Donnell, Mente, \& Yusuf, 2015)

\section{Grades of hypertension}

Subjects in the control group $(66.7 \%)$ had grade 1 hypertension with SBP mean of $156.72 \pm 10.25$ and $156.22 \pm 10.70$ in the intervention group with the same percentage. This study did not directly examine the awareness of subjects to hypertension, but this condition may explain the lack of awareness of subjects to an increased in BP. The increase in BP often occurs without any obvious symptoms so unconsciously and often leads to a low awareness of hypertension (Wang et al., 2015).

\section{Scientific principles of cupping}

Negative air pressures differences decreased SBP in the control group up to $0.71 \%$ while a larger decrease of $2.81 \%$ was the intervention group. The decrease of DBP in the control group was $1.69 \%$ while in the intervention group was $3.02 \%$. Therefore, the pressure of 540 mbar yielded greater effect on decreasing DBP than the pressure of 400 mbar. Cupping seems to be related in principle to the scientific principles governing excretory functions of the kidney to the extent that cupping may be regarded as an 
artificial kidney that performs skin capillary filtration and size-dependent excretion of particles at pressures higher than filtration pressures in renal glomeruli. Skin barrier inhibits the excretion of metabolic waste, whereas the cupping therapy incisions open the skin barrier and enhance the natural excretory role of the skin (El Sayed et al., 2013). The capability of 540 mbar negative air pressures yielded better effect on blood pressure lowering can be explained, as the affected region within the soft-tissue layers produced by cupping is quite localized; it should be possible with an appropriate vacuum pressure level to stimulate individual acupuncture points underneath the skin layers. The normal stress levels at mid-thickness of the skin layer for the different applied vacuum pressure loads show that the peak tensile stresses just inside the rim of the cup were substantially higher for the higher suction load. Higher negative air pressure load (540 mbar), stimulates greater acupuncture points effect than the lower pressure (400 mbar), cupping also decreases BP by stimulating the acupuncture points (Tham et al., 2006).

\section{Statistical analysis and comparisons}

The difference on negative air pressure load provided did not affect significantly on the decrease of BP for a long time; however, it provides a rapid effect yet did not last long. The effects on BP lowering were significantly and progressively more influence by determining the cupping point and the number of cupping sessions performed. A study by Aleyeidi, Aseri, Matbouli, et al. (2015) reported different results, 3 cupping sessions were performed, and one cupping point was similar to this study (al-kahil). SBP measurement on week IV obtained the effect size 0.50 (medium) and week VIII 0.44 (medium), DBP on week IV 0.030 (low) and week VIII 0.30 (low). When comparing the mean BP readings between the two groups after 4 weeks of follow-up, there was a significant difference in SBP values $(p=0.046)$ but not in DBP values $(p=0.681)$. After 8 weeks of follow-up, significant differences persisted within the cupping group, for SBP and DBP ( $p=0.002$ and 0.004 , respectively). When comparing the mean BP between the two groups, the differences in the SBP and DBP values were not significantly different between the groups ( $p=0.129$ and 0.881 , respectively). This study had shown that cupping on Alkahil point affected BP lowering progressively that lasts for 4 weeks.

A study by Aleyeidi, Aseri, Matbouli, et al. (2015) is consistent with that of Zarei et al. (2012) that cupping was performed only on al-kahil point and BP was measured at day 42 that produced effect size 0.73 (high) in decreasing BP. Cupping point in this study was similar to the point used in Zarei's study that proved significant BP-lowering obtained in more than two weeks. This explained BP measurements within one week provided a rapid effect but did not last long, which describes the blood pressure measurement within one week proves the rapid decrease but had no effect in the long term where there is a rise in blood pressure in $<2$ weeks. This study found cupping effect obtained within long-term with repeated sessions on certain points and appropriate negative air pressures load to decrease BP in hypertensive patients.

Aleyeidi, Aseri, Matbouli, et al. (2015) suggested that a greater number of incisions at each cupping site (10 to 15 incisions) might yield more blood collection and consequently produce better results. Furthermore, they did not recommend undergoing 
three consecutive sessions, each spaced a day apart, because there was no BP difference between those who did one, two, or three sessions. One session might be enough to achieve the required result. This study found different results compared to the study mentioned above, one cupping session yielded medium effect size (SBP 0.40 and DBP 0.46), thus when comparing to study by Zarei et al. (2012) that produced high effect size 0.73 yielded by performed 3 cupping sessions.

The differences were not significant between the pressure of 400 mbar and 540 mbar in lowering BP. The decrease in the mean of SBP at cupping pressure on 540 mbar about $3.67 \pm 3.31(2.81 \%)$ was not clinically significant. Despite the SBP decreased, but still, in grade 1 hypertension category, the SBP had not reached the normal blood pressure category. The decline in mean SBP was small allegedly influenced by the $66.7 \%$ of subjects in grade 1 hypertension category. Makridakis and DiNicolantonio (2014) reported the majority of hypertensive patients who receives treatment for lowering blood pressure would not achieve the level of 140/90 $\mathrm{mmHg}$, although received three types or more antihypertensive drugs.

Furthermore, hypertension management to decrease BP requires treatment combination. A qualitative study by Anthony, Valinsky, Inbar, Gabriel, and Varda (2012) reported people with hypertension tend to see hypertension not as a disease but as a risk factor for myocardial infarction or stroke. They do not view it as a continuous, degenerative process of damage to the vascular system, but rather as a binary risk process, within which one can be either a winner (not become ill) or a loser. This makes non-adherence to treatment a gamble with a potential positive outcome. Most subjects overestimated the effect of stress as a causative factor believing that a reduction in levels of stress is the most important treatment modality. Patients were most likely to adopt a treatment which is a compromise between their physician's suggestions and their own understanding of hypertension.

This study found that BP decreased existed in one week; thus, it required another complementary therapy as a booster after a week I to persist BP decrease until week II or more. Considering to repeat cupping at the same point can only perform after 4 weeks (Kusyati, 2015), the researchers recommend to support cupping with negative air pressure loads of 400-540 mbar at 3 points, low-sodium diet modification and physical exercise activities (Albert \& Effiong, 2015) and yoga (Wolff, Sundquist, Lönn, \& Midlöv, 2013) with the intention to decrease BP. The pattern recommended was cupping followed with Kundalini yoga at the week I then continued with diet modification and exercise to week II after cupping. Kundalini yoga exercises are encouraged to perform at home for a total of 15 minutes a day. The two yoga exercises are 1) "Left nostril breathing"- deep breaths in and out through the left nostril while sitting or lying down, with the right nostril closed off by the right thumb or an earplug ( \pm 11 minutes), and 2) "Spinal flex"-movement that alternates between flexing the spine forwards (arching) and relaxing the spine back in time with deep breaths while sitting in a chair ( \pm 4 minutes). Kundalini yoga was relatively easy to perform and is suitable for all ages and levels of fitness (Wolff et al., 2013). 
Negative vacuum pressure in this study about 400 mbar and 540 mbar were an estimation referenced to aforementioned previous study. Thus the pressure differences in each cup during cupping were not quite accurate. It could be slightly more and less depending on the subcutaneous tissue and the elasticity of skin surface. However, higher pressure yielded better effect in decreasing BP. Low-sodium diet modification and physical exercise activities were not controlled during the study. Therefore, it may possibly influence the study results. Further study about cupping in decreasing BP with diet modification and physical exercise factors controlling is required to evade the bias of the study. Furthermore, other factors that may modify cupping therapeutic effects are the selection of points for treatment, the frequency of cupping treatment and nonspecific factors such as patient-practitioner relationship and belief in the cupping therapy.

\section{CONCLUSION}

Negative air pressure load of 540 mbar on cupping yielded greater effect decreasing SBP and DBP for up to 2 weeks. Negative air pressure loads on cupping with the intention to decrease BP in male hypertensive patients with grade 1 and 2 should be considered between 400-540 mbar that equal two times to maximum three times pumping using standard cupping manual hand pump. We recommend the cupping with 400-540 mbar, in conjunction with any anti-hypertension medications, to treat hypertension. Further studies were also needed to investigate the efficacy of cupping alone, without concomitant anti-hypertension medications, or other conditions of illness that require distinctive treatment such as diabetes, stroke, asthma, and bronchitis.

\section{REFERENCES}

Ahmedi, M., \& Siddiqui, M. R. (2014). The value of wet cupping as a therapy in modern medicine - an Islamic perspective. Webmed Central Alternative Medicine, 5(12). doi: WMC004785

Albert, U. K., \& Effiong, J. H. (2015). Risk factors and anthropometric variables of young people with essential hypertension in Uyo, Akwa Ibom State. British Journal of Medicine \& Medical Research, 10(8).

Aleyeidi, N., Aseri, K., \& Kawthar, A. (2015). The efficacy of wet cupping on blood pressure among hypertension patients in Jeddah, Saudi Arabia: A randomised controlled trial pilot study. Alternative \& Integrative Medicine, 4(1). doi: 10.4172/2327-5162.1000183

Aleyeidi, N., Aseri, K. S., Matbouli, S. M., Sulaiamani, A. A., \& Kobeisy, S. A. (2015). Effects of wet-cupping on blood pressure in hypertensive patients: a randomized controlled trial. Journal of Integrative Medicine, 13(6), 391-399.

Anthony, H., Valinsky, L., Inbar, Z., Gabriel, C., \& Varda, S. (2012). Perceptions of hypertension treatment among patients with and without diabetes. BMC Family Practice Journal, 13(24), 7. doi: 10.1186/1471-2296-13-24

Asayama, K., Thijs, L., Brguljan-Hitij, J., Niiranen, T. J., Hozawa, A., Boggia, J., . . . Ohkubo, T. (2014). Risk stratification by self-measured home blood pressure across categories of conventional blood pressure: a participant-level metaanalysis. Public Library of Science Journal, 11(1). doi: e1001591

Bild, D. E., McClelland, R., Kaufman, J. D., Blumenthal, R., Burke, G. L., Carr, J. J., . . . Szklo, M. (2014). Ten-year trends in coronary calcification in individuals 
without clinical cardiovascular disease in the multi-ethnic study of atherosclerosis. Public Library of Science Journal, 9(4). doi: e94916

Doonan, R. J., Hausvater, A., Scallan, C., Mikhailidis, D. P., Pilote, L., \& Daskalopoulou, S. S. (2010). The effect of smoking on arterial stiffness. Hypertension Research 33, 398-410.

El Sayed, S., Mahmoud, H., \& Nabo, M. (2013). Medical and scientific bases of wet cupping therapy (Al-hijamah): in light of modern medicine and prophetic medicine. Alternative \& Integrative Medicine, 2013.

Fernández-Atucha, A., Izagirre, A., Fraile-Bermúdez, A., Kortajarena, M., Larrinaga, G., Martinez-Lage, P., . . . Gil, J. (2017). Sex differences in the aging pattern of renin-angiotensin system serum peptidases. Biology of Sex Differences Journal 8(5), 8. doi: DOI 10.1186/s13293-017-0128-8

Huber, R., Emerich, M., \& Braeunig, M. (2011). Cupping-is it reproducible? Experiments about factors determining the vacuum. Complementary Therapies in Medicine, 19(2), 78-83.

Kalra, S., Kalra, B., \& Agrawal, N. (2010). Combination therapy in hypertension: An update. Diabetology and Metabolic Syndrome Biomed Central Journal, 2(44), 11. doi: 10.1186/1758-5996-2-44

Kusyati, E. (2015). Bekam Sebagai Terapi Komplementer Keperawatan [Cupping as a complementary therapy in Semarang]. Semarang: Gabardin Jaya.

Kusyati, E., Hartono, S., \& Hastuti, W. (2014). Pengaruh Arah Putaran Jarum Bekam Basah Terhadap Tekanan Darah Penderita Hipertensi Di Kedung Mundu Semarang [Effects of Wet Cupping Needle Boundary Directions on Blood Pressure in Hypertensive Patients in Kedung Mundu Semarang]. Prosiding Konferensi Nasional II PPNI Jawa Tengah, 66-75.

Luo, J., Xu, H., \& Liu, B. (2015). Real world research: a complementary method to establish the effectiveness of acupuncture. BMC Complementary and Alternative Medicine, 15(1), 1. doi: 10.1186/s12906-105-0676-6

Makridakis, S., \& DiNicolantonio, J. J. (2014). Hypertension: empirical evidence and implications in 2014. Open Heart British Medical Journal, 1, 8. doi: 10. 1136/openhrt-2014-000048

McNeil, S., \& Parkosewich, J. (2013). A 5-Minute rest period improves the accuracy of blood pressure measurement at time of patient intake. Continuing Nursing Education: AMBJ1505.

O'Donnell, M., Mente, A., \& Yusuf, S. (2015). Sodium Intake and Cardiovascular Health. Circulation Research Journal of American Heart Association, 2015(116), 1046-1057. doi: 10.1161/CIRCRESAHA.116.303771

Papakonstantinou, E., Kechribari, I., Sotirakoglou, K., Tarantilis, P., Gourdomichali, T., Michas, G., . . . Zampelas, A. (2016). Acute effects of coffee consumption on self-reported gastrointestinal symptoms, blood pressure and stress indices in healthy individuals. Nutrition Journal, 15(26), 1-11. doi: DOI 10.1186/s12937016-0146-0

Polosa, R., Morjaria, J. B., Caponnetto, P., Battaglia, E., Russo, C., Ciampi, C., . . . Bruno, C. M. (2016). Blood pressure control in smokers with arterial hypertension who switched to electronic cigarettes. International Journal of Environmental Research and Public Health, 13(1123), 1-14. doi: doi:10.3390/ijerph13111123 
Posadzki, P., Cramer, H., Kuzdzal, A., Lee, M. S., \& Ernst, E. (2014). Yoga for hypertension: a systematic review of randomized clinical trials. Complementary Therapies in Medicine, 22(3), 511-522.

Pujiastuti, R. S. E. (2016). Fostering soft skills in nursing through caring theory in nursing ethics course. The Proceeding of 7th International Nursing Conference: Global Nursing Challenges in The Free Trade Era, 8-9 April 2016, Surabaya.

Tham, L., Lee, H., \& Lu, C. (2006). Cupping: from a biomechanical perspective. Journal of Biomechanics, 39(12), 2183-2193.

Tolonen, H., Koponen, P., Naska, A., Männistö, S., Broda, G., Palosaari, T., \& Kuulasmaa, K. (2015). Challenges in standardization of blood pressure measurement at the population level. BMC Medical Research Methodology, 15(1), 1-11. doi: 10.1186/s12874-015-0020-3

Wahdah, N. (2011). Menaklukkan hipertensi dan diabetes (mendeteksi, mencegah, dan mengobati dengan cara medis dan herbal) [Dealing with hypertension and diabetes (detecting, preventing, and treating in medical and herbal perspectives)]. Yogyakarta: MultiPress.

Wang, H., Wong, M., Mok, R., Kwan, M., Chan, W. M., Fan, C., . . . Griffiths, S. (2015). Factors associated with grade 1 hypertension: implications for hypertension care based on the dietary approaches to stop hypertension (DASH) in primary care settings. BMC Family Practice, 16(1), 26. doi: 10.1186/s12875015-0239-4

Wolff, M., Sundquist, K., Lönn, S. L., \& Midlöv, P. ( 2013). Impact of yoga on blood pressure and quality of life in patients with hypertension - a controlled trial in primary care, matched for systolic blood pressure. BMC Cardiovascular Disorders Journal, 13(111), 9. doi: doi:10.1186/1471-2261-13-111

Xiong, X., Li, X., Zhang, Y., \& Wang, J. (2015). Chinese herbal medicine for resistant hypertension: a systematic review. British Medical Journal, 5(1). doi: e005355

Zarei, M., Hejazi, S., Javadi, S. A., \& Farahani, H. (2012). The efficacy of wet-cupping in the treatment of hypertension. ARYA Atherosclerosis Journal, S145-S148.

Zhao, X.-F., Hu, H.-T., Li, J.-S., Shang, H.-C., Zheng, H.-Z., Niu, J.-F., . . Wang, S. (2015). Is acupuncture effective for hypertension? A systematic review and meta-analysis. Public Library of Science Journal, 10(7). doi: e0127019

Zhu, W. (2016). Opinion p < 0.05, <0.01, <0.001, <0.0001, <0.00001, <0.000001, or $<0.0000001$. . Journal of Sport and Health Science, 5(1), 77-79. doi: http://dx.doi.org/10.1016/j.jshs.2016.01.019 